\title{
A WOMEN SECURE MOBILE APP FOR EMERGENCY USAGE (GO SAFE APP)
}

\author{
Divya $\mathrm{S}^{\mathbf{1}}$, Vinitha $\mathrm{M}^{\mathbf{2}}$, Logeshwari $\mathrm{B}^{\mathbf{3}}$, Indumathi $\mathrm{P}^{\mathbf{4}}$ \\ ${ }^{I}$ Assistant Professor, Department of CSE, RVS Technical Campus-Coimbatore, India \\ ${ }^{2} U G$ Scholar, Department of CSE, RVS Technical Campus- Coimbatore, India \\ ${ }^{3} U G$ Scholar, Department of CSE, RVS Technical Campus- Coimbatore, India \\ ${ }^{4} U G$ Scholar, Department of CSE, RVS Technical Campus- Coimbatore, India
}

\begin{abstract}
Many unfortunate incidents have been taking place. Problems may come from any direction such as walking on the road after the work, going to super market or many other reasons for which they go alone. People at home are not sure of their return safely. In order to overcome such problems the GO SAFE (security app) mobile based application is not only necessary to use but also plays a pivotal role with android software. The usage of smart phones equipped with GPS navigation unit have increased rapidly. The "GO SAFE" application is mainly developed to safeguard. By clicking on the buttons (power \& volume button) alert message is sent. Application communicates the user's location to the registered contacts in the form of message. Thus, it acts like a sentinel following behind the person till the user feels she is safe. Also, the registered contacts and GPS location are saved from time to time in a database.
\end{abstract}

Keywords: Apps, Android, Mobile, Safety. Etc...

\section{INTRODUCTION}

In today's world, it is not safe for a person to travel alone at night especially for women, it will be high time to travel alone because a woman is not highly strong as men to protect herself from them. The good way to reduce chances in becoming a victim of violent crime (robbery, sexual assault, rape, domestic violence) is to identify and call on resources to help out of unsafe situations. Whether in instant trouble or got separated from friends during night and do not know to reach home, having these apps on phone can diminish our risk and bring assistance when we require it. In this paper, it is presented GO SAFE, an application for smart phones working over android platform. The motto in developing this app is to provide a safe environment through smart phone as today most of the people are carrying smart phones to wherever they go.

Of course, the Delhi Nirbhaya case has made the Government to make the laws tougher, but even though the sexual crime rate in India have not decreased. So, it is better to take our own safety measures rather than becoming a victim of those crimes.

This paper is organised as follows. Section II describes the literature survey of the existing apps and the related work of creating the application. Section III presents the functionalities and key features of the application. Consequently, the working of the application is described in the section IV. The section V presents the testing results of the application after installing in the smart phone. Finally, section VI concludes the paper and presents the future work for the paper.

\section{RELATED WORK}

As a part of literature survey, it is investigated some applications of safety that already exist in market. The aim is to observe how these applications work and to see how they can be improved and how are they different. To date it is identified that the following Android Apps of security are good and are offering relatively similar service.

\subsection{Women's Security}

The app is developed by AppSoftIndia. The key features of the app are: the user has to save some details. These details include: Email address and password of the user, Email address and mobile number of the recipient and a text message. Then, app is loaded as a "widget", so that when the user touches the app, it alerts the recipient. Another key feature of app is that it records the voice of surroundings for about 45 seconds and this recorded voice, text message containing location co-ordinates of the user is sent to the recipient mobile number.

\subsection{Bsafe- Personal Safety App}

The app is developed by Bipper Inc. On March 6, 2015. The app's motto is "Never Walk Alone". This app helps the user to create a gang of 'Guardians' and SOS message will be received by them when the user is in trouble. Also another good feature of this app is one of the guardians will also be called. The SOS message also includes location of user via GPS. The user can also enable the GPS tracker and let the friends know location at any time. 


\subsection{Safetipin- Complete Safety App}

The is a privacy security app having the troop of features; GPS tracking, emergency, important contact numbers, directions to safe locations, pins displaying unsafe and free from danger areas and a Safety Score. It drives in advance of exemplary women safety apps, and presents a vast range of features, so that they will help to practically plan and can give a counter attack to those spots in the locality. When a person is going to move to a new locality that is unknown to him and if he or she want to know the safe areas, then this app will be much helpful providing the user a map based view of the locality along with its safety score. Also, the person can select the areas on those he or she excited to go and can get knowledge about the risks of hassles about the area, so they can finally take safety measures.

\subsection{Police Nearby}

The app is developed by Big Systems in 2013.The police nearby scanner android app is built with the aim to connect citizens \& students to their nearest police stations city wise at one click and will permit the community to become more involved right from your Android Smart phones. Any local, state, or school, College police department as well as other law enforcement agencies can use Police scanner Android App to provide you with enhanced service and get better communication. Police nearby app is free to download without signup.

\section{EVALUATION}

The motto is to develop an application for android users to keep track of user through several functions. This application uses GPS for identifying the location of the user in trouble, uses a database in which the complete details to which the information has to be sent and the required information like GPS co-ordinates will be stored. The complete system can be divided into three modules:

1. First module can be the victim's phone which uses GPS tracking application sending information of the location to the database continuously.

2. Second module can be the database in which the contact details like police control room, family, friends etc are saved.

3. Third module can be the mobile phone of friends or family or police to which the information of GPS coordinates will be sent.

4. By pressing on the power and increase volume button, initially it identifies the location of the user through Global Positioning System (GPS). Then, it sends the latitude and longitude co-ordinates of the user's location to the registered contacts.

\subsection{Overview}

The block diagram depicted below shows the exact flow of control of the android application. Here the database acts as a storing media between the two mobile devices. The database information i.e. to which database the information has to be sent, the URL of the database is coded itself in the application. From the database, the location co-ordinates is sent to the registered contacts of the user.

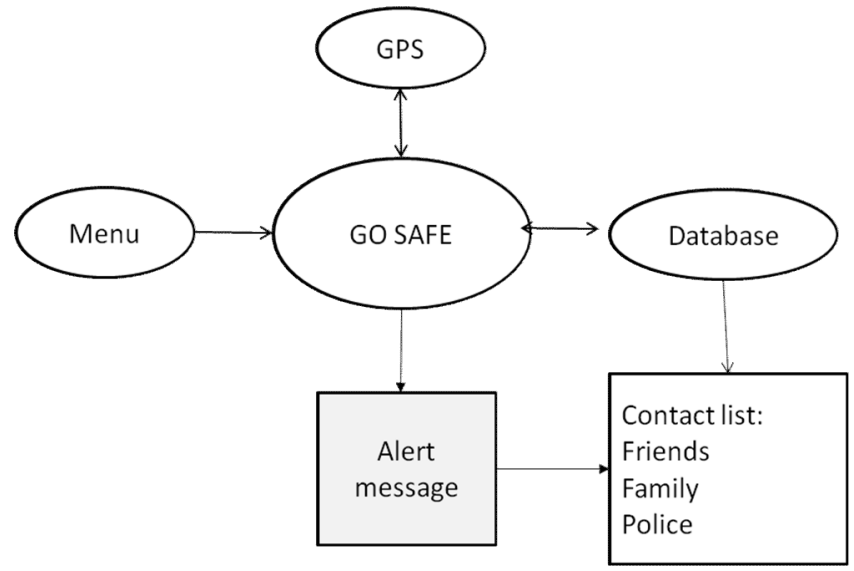

\section{SYTEM WORKING}

The working of the application is divided into three major sections. They are described as follows:

a) Initially, when the app is touched it asks for users details like name of the user,contacts from whom we hire help.The contacts who will respond immediately must be saved like family, friends or police. These contacts are called registered contacts; they are called so because they are registered to the application. After entering the contact details, save button must be touched so that those will be saved and after to these the user information will be sent when the person is in danger.

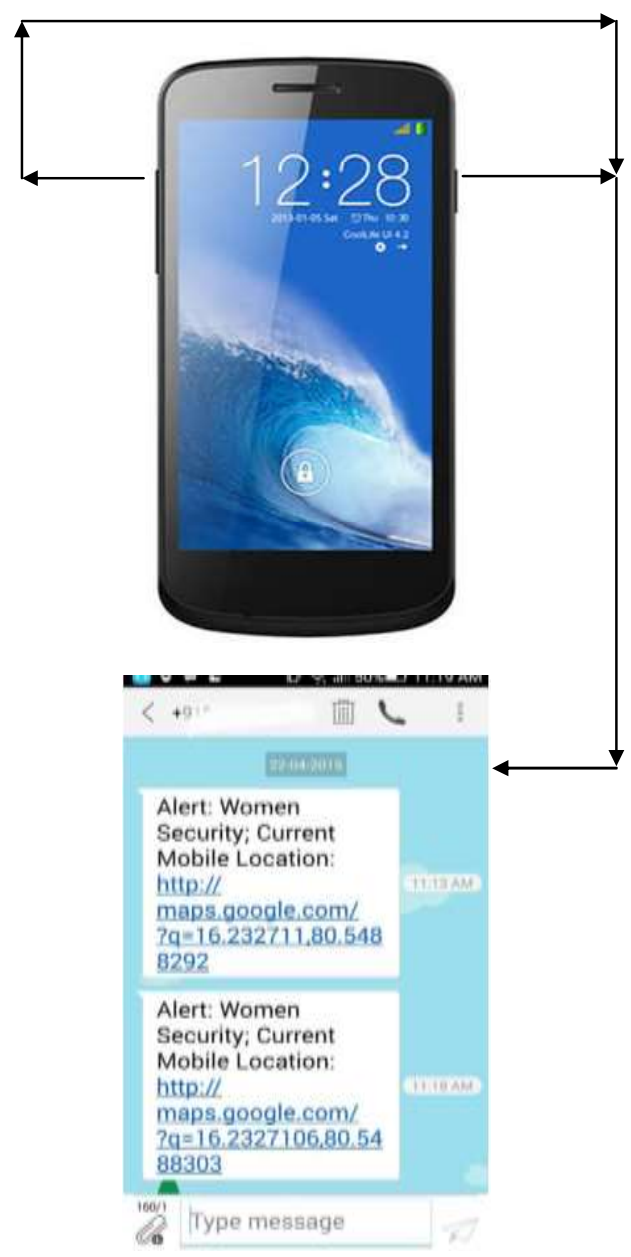


b) Click on the combination of buttons, the GPS information (the GPS information can be in the form of latitude and longitude co-ordinates of the user's location or in the form of URL which leads to the location of the person through any stock map application ) and the alert message is also sent through it.
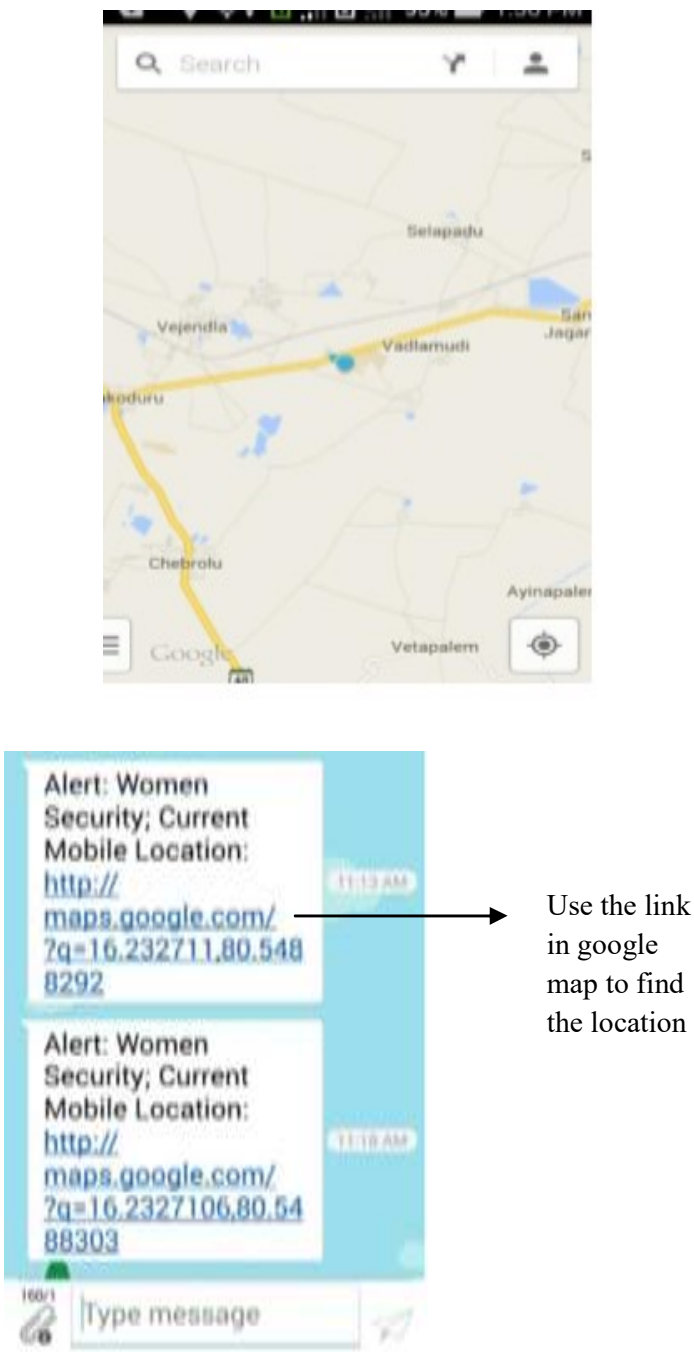

c) This section describes the primary working of the database. The information that is sent to the database is in turn sent to the registered contacts continuously.

\section{CONCLUSION}

This paper describes the application, GO SAFE that is designed in android platform for safety measures with the aid of recent improvements in mobile technology. This application helps the tracking of the root device through GPS which will help the law enforcement authorities to rescue the person in danger as quickly as possible from the anti- social elements. For future development, this application can be integrated with the law enforcement database (eg.city police control room database) instead of experimental database used here in the project.Thus, this app can help in a big way to rescue the women or men from unsafe conditions.

\section{REFERENCES}

[1]. Doulamis, A.; Pelekis, N.; Theodoridis, Y., "EasyTracker: An Android Application for Capturing Mobility Behavior," 2012 16th Panhellenic Conference on Informatics (PCI), vol., no., pp.357,362, 5-7 Oct. 2012 .

[2]. Saranya, J.; Selvakumar, J., "Implementation of children tracking system on android mobile terminals," 2013 IEEE International Conference on Communications and Signal Processing (ICCSP), vol., no., pp.961,965, 3-5 April 2013.

[3]. http://www.mappsafe.com/blog-1-feb-14-threereasons-why-mobile-technology-will-reduce-violenceagainst-women .

[4]. Nicole Westmarland, Mariann Hardey, et al. "Protecting Women's Safety? The use of smartphone ,apps in relation to domestic and sexual violence ${ }^{\text {ee, }}$ Durham University, Durham centre for research into violence and abuse (2013).

[5]. Mason, C and Shoshana Magnet, "Surveillance studies and violence against women", surveillance \& society 10(2):105 - 118 (2012).

[6]. Elliott, J. and McCartan K. The Reality of Trafficked People ${ }^{e e}$ s Access to Technology. The Journal of Criminal Law 77(3): 255-273(2013).

[7]. Dimond, J.P., Fiesler, C. and Bruckman, A.S. Domestic violence and information communication technologies, Interacting with Computers, 23(5): 413-421(2011).

[8]. Portio Research. Portio research mobile factbook 2011. Chippenham, UK. Retrieved from http://www.portioresearch.com/Portio\%20Research\%2 0Ltd\%20Mobile\%20Factbook\%202011.pdf (2011).

[9]. Ofcom. Children and Parents: Media Use and Attitudes Report (2012).

[10].Dennison, L., Morrison, L., Conway, G., \& Yardley, L. (2013).Opportunities and Challenges for Smartphone Applications in Supporting Health Behavior Change: Qualitative Study, Journal of medical Internet research, 15(4): e86.

[11].Qualcomm Wireless ReachTM, Vital Wave, and GSMA. Transforming Women 's Livelihoods Through Mobile Broadband. Report, February 2014. Available at: http://www.qualcomm.com/mwomenreport

[12].Vodafone. "Connected Women: How mobile can support women "s economic and social empowerment". Report, March, 2014 